\title{
An Investigation through the Pharmacotechnical Factors-to Develop a Method to Replace a Super Disintegrant in an Immediate Release Tablet
}

\author{
Dhanish Joseph', S.R. Suseem ${ }^{2, *}$ \\ 'Department of Pharmaceutics, Nirmala College of Pharmacy, Muvatupuzha, Ernakulam, Kerala, INDIA. \\ ${ }^{2}$ Department of Chemistry, School of Advanced Sciences, Vellore Institute of Technology, Vellore, Tamil Nadu, INDIA.
}

\begin{abstract}
Objectives: The present work aim to identify the process parameters and technical parameters of granules that affect the disintegration time of an IR tablet. There by utilizing this knowledge to develop an IR tablet without any Super Disintegrants (SD). Methods: The experiments were designed using Design-Expert ${ }^{\oplus}$. A two factorial design at two levels $(-1,+1)$ were selected. The study evaluated the effect of particle size and Binder concentration (BC) on Disintegration Time (DT), Hardness and Compressibility index (Cl). Discussion: The $\mathrm{Cl}$ below $16 \%$ can be achieved for the granules prepared with particle size $>670 \mu \mathrm{m}$ and binder concentration $>18.56 \mathrm{mg}$ for PVP K 30. The particle sizes do not possess any impact on disintegration time. The granules prepared at the $250 \mu$ size and $600 \mu$ size shoes similar disintegration time. However, the particle size affects hardness and $\mathrm{Cl}$. The $\mathrm{BC}$ has a strong impact on hardness, $\mathrm{Cl}$ and DT. Even though the particle size does not have a direct impact on DT, it affects the hardness, which has a greater impact on DT. Conclusion: The study identified the technical methods and suggests certain formula to attain the low disintegration
\end{abstract}

time, excellent hardness for an IR tablet and fair flow property for the prepared granules. The particle size has a direct impact on the hardness of the tablet. The formula serves as an excellent alternative for SD at an industrial level, to make the drug product more economical and more effective.

Key words: Disintegration Time, Potent Drug, Dissolution enhancement, Design Expert, Compressibility Index, Particle Size and Hardness.

\section{Correspondence}

Dr. SR Suseem,

Department of Chemistry, School of Advanced Sciences, Vellore Institute of Technology, Vellore-632014, Tamil Nadu, INDIA.

Phone no: +91-8903476378

Email: srsuseem@vit.ac.in

DOI: 10.5330/ijpi.2019.4.31

\section{INTRODUCTION}

Micromeritics is the science of small particles. The particle size, shape and surface area is directly related to release of drug from dosage form, absorption of drug and its bioavailability, Physical stability and dose uniformity. In the development of tablets or capsules the particle size contributes very much to achieve the desired flow property for the granules. ${ }^{1}$ The bioavailable fraction of a drug determines its fate in the biological system. Thus, to release the drug from the delivery system and to improve its rate of absorption all the immediate release drug delivery systems are developed with a Superdisintegrants. ${ }^{2}$ Majority of SD has swelling as the basic mechanism of disintegration ${ }^{3}$ and it is very well applicable in case of many drug molecules. Use of SD in the highly potent drug formulation has certain drawbacks. ${ }^{4}$ Development of an IR tablet for a potent drug with a SD does not produce the same rate of absorption as that of a low potent drug makes. ${ }^{5}$ As the SD swells the potent drug gets entrap or bind with the SD gel produce a slow release pattern. Thus, it is a rate limiting step for absorption. ${ }^{6}$ This situation must be very critically monitored for a high potent drug. Thus, this study aims to develop an IR tablet only by adjusting the Micromeritics of granules without the support of any SD or even a disintegrant. The particle size of granules Other than disintegrants the DT depends on hardness of a tablet, particle size of granules and strength of the granules. The hardness of tablet depends on strength of granules and strength of granules depends on binder con- centration. Thus, these properties are interrelated. A pilot study conducted in this regard identified the difference in disintegration time with respect to change in granular particle size.

\section{MATERIALS AND METHODS}

\section{Materials}

The materials used for tablet preparation include a model drug Flurbiprofen purchased from Chemdyes Corporation Rajkot. PVP K 30 Purchased from yarrochem products Mumbai, Lactose nice chemicals, Talc and Magnesium Stearate purchased from lobachemie.

\section{Experimental Design}

In this study a two factor, multiple level $(-1,+1)$ full factorial design was used to construct the mathematical model. The experiments were designed using Design-Expert. The level of independent variable used to construct the full factorial design is given in Table 1. All the three responses were mutually compared with the two factors. The dependent variable or the responses are compressibility index, disintegration time and hardness of tablet. Totally 12 experimental run were performed and tested according to factorial design.

\section{Preparation of tablet}

The granules were prepared based on the above design using Flurbiprofen (1mg), PVP K 30, lactose by wet granulation method and lubricated with talc $(0.5 \%)$ and magnesium stearate (1\%). ${ }^{7}$ To study the exact effect of particle size on disintegration time the tablets were prepared without disintegrants. The granules were prepared for a batch size for 1000 tablets of $100 \mathrm{mg}$. The binder solution was prepared by dissolving the desired quantity of PVP K 30 in $20 \mathrm{ml}$ water. The drug was properly blended with lactose and granulated using the prepared binder solution. The granules 
wet sieved through $\# 60$, \#30 for $250 \mu$ and $600 \mu$ respectively and dried at $40^{\circ} \mathrm{C}$ for $15 \mathrm{~min}$. Dry sieved through \#60 pass \# 70 retained and \# 30 pass \#35 retained for $250 \mu$ and $600 \mu$ respectively. After the evaluation of pre-compression parameters (CI), ${ }^{8}$ the granules were compressed using Ridhi mini press, $6 \mathrm{~mm}$ round concave punch and evaluated for the hardness $^{9}$ and disintegration time. ${ }^{10}$

\section{Evaluation Test}

The CI was measured using electro lab (ETD1020X) tapped density apparatus. USP Method 1 using $100 \mathrm{ml}$ graduated cylinder with a mass of $130 \pm 16 \mathrm{~g}$ and $250 \pm 15$ taps from a height of $3 \pm 0.2 \mathrm{~mm}$. The granules were tapped for 10,500, 1250 taps and the corresponding volume $\mathrm{V}_{10}$, $\mathrm{V}_{500}, \mathrm{~V}_{1250}$ was noted. If the difference between $\mathrm{V}_{500}$ and $\mathrm{V}_{1250}$ is less than or equal to $1 \mathrm{ml} \mathrm{V}{ }_{1250}$ is considered as the tapped volume. But if it is greater than $1 \mathrm{ml}$ repeat the tapping in 1250 increments until the difference between the successive taps are less than or equal to $1 \mathrm{ml}$. The Disintegration test was performed in Esico International (901) apparatus using water. As per USP procedure for uncoated tablets without disk. The hardness was determined using Monsanto hardness tester.

\section{RESULTS}

The 12 runs in the experimental design along with the observed responses are briefly presented on Table 2 . The statistical significance of independent factors on the responses is tested by ANOVA. In case of compressibility index interaction between binder concentration and particle size is significant $(P<0.007)$ whereas its individual effect is least significant. In case of disintegration time the binder concentration is more significant $(P<0.0001)$ than particle size. The individual effect and interaction effect of particle size and binder concentration is highly significant $(P<0.0001)$ to get the proper hardness.

\section{Compressibility index}

Figure 1 indicates the interaction between the particle size and $\mathrm{BC}$ on CI. The CI increases slightly with increase in particle size from 250 to $600 \mu \mathrm{m}$. As the $\mathrm{BC}$ ranges from 2 to $15 \mathrm{mg}$. The CI has decreased slightly. At lower BC of granules, as the particle size increases from two 250 to $600 \mu \mathrm{m}$ the compressibility index also increased from $18.11 \%$ to $22.63 \%$.
Whereas the reverse is the case at higher Binder concentration, as the particle size increases the CI decreases from $21.48 \%$ to $18.58 \%$.

\section{Disintegration time}

The effect of particle size and BC on DT has evaluated. The effect of Binder is a well-known factor whereas the roles of particle size on DT need to be analyzed. The tablets are prepared without any disintegrants. Figure 3 shows the interaction graph between the binder and granular size on DT. The particle sizes do not possess any impact on DT the granules prepared at the $250 \mu$ size and $600 \mu$ size shoes similar DT. ${ }^{11-13}$ The tablets were prepared at same compression force the data concludes that the observed result is only because of the impact of $\mathrm{BC}$ and particle size do not have any effect on increasing or decreasing the DT.

\section{Hardness}

The analysis of variance shows the model is significant with a $p<0.0001$. The interaction effect of $\mathrm{BC}$ and particle size on hardness was studied. Figure 4 explain the interaction graph. The one-factor graph shows as the particle size increase from $250 \mu$ to $600 \mu$ the hardness decrease from $11.4 \mathrm{~kg}$ to $7.4 \mathrm{~kg}$. In the interaction graph, at $600 \mu$ particle size, the hardness is less as compared with $250 \mu$. Figure 5 indicates the contour plot for effect of particle size and BC on hardness. Hardness from $4-12 \mathrm{~kg}$ is achieved based on different levels of BC.

\section{DISCUSSION}

The lower CI can be achieved either by increasing the particle size ${ }^{14}$ or by decreasing the $\mathrm{BC}$ but decreasing the $\mathrm{BC}$ below and an optimized level is not possible as it may affect the flow property and it may affect the hardness of the granules thus an optimum BC must be maintained. At this particular Binder level, to decrease the compressibility index the particle

Table 1: Independent Variables of the Full Factorial Design.

\begin{tabular}{ccc}
\hline & \multicolumn{3}{c}{ Coded values } \\
\cline { 2 - 3 } Independent factors & -1 & +1 \\
\hline Binder Concentration $(\mathrm{mg})$ & 2 & 15 \\
Particle Size $(\mu)$ & 250 & 600 \\
\hline
\end{tabular}

Table 2: The Randomized Runs of the Full Factorial Design and the Observed Responses.

\begin{tabular}{cccccc}
\hline & Factor 1 & Factor 2 & Response 1 & Response 2 & Response 3 \\
\cline { 2 - 6 } & $\begin{array}{c}\text { A:A:Binder } \\
\text { Concentration }\end{array}$ & $\begin{array}{c}\text { B:B:Particle } \\
\text { Size }\end{array}$ & $\begin{array}{c}\text { Compressibility } \\
\text { Index }\end{array}$ & $\begin{array}{c}\text { Disintegration } \\
\text { Time }\end{array}$ & Hardness \\
1 & Mg & Microns & \% & Min & Kg \\
2 & 2 & 250 & 20.833 & 1.5 & 8.6 \\
3 & 2 & 250 & 15 & 2 & 9 \\
4 & 2 & 250 & 18.519 & 1.8 & 10 \\
5 & 15 & 250 & 22 & 11.38 & 12 \\
6 & 15 & 250 & 22.44 & 12 & 15 \\
7 & 15 & 250 & 20 & 13 & 3.6 \\
8 & 2 & 600 & 23.63 & 1.4 & 4 \\
9 & 2 & 600 & 23.33 & 2 & 3 \\
10 & 2 & 600 & 20.93 & 2.4 & 11 \\
11 & 15 & 600 & 18.75 & 11.15 & 12 \\
12 & 15 & 600 & 19 & 13.5 & 12 \\
\hline
\end{tabular}


Table 3: Constraints for optimization.

\begin{tabular}{ccccccc}
\hline $\begin{array}{c}\text { Name A:A:Binder } \\
\text { Concentration }(\mathrm{mg})\end{array}$ & $\begin{array}{c}\text { Goal } \\
\text { minimize }\end{array}$ & $\begin{array}{c}\text { Lower } \\
\text { Limit 2 }\end{array}$ & $\begin{array}{c}\text { Upper } \\
\text { Limit 7 }\end{array}$ & $\begin{array}{c}\text { Lower } \\
\text { Weight 1 }\end{array}$ & $\begin{array}{c}\text { Upper } \\
\text { Weight 0.1 }\end{array}$ & Importance 3 \\
\hline $\begin{array}{c}\text { B:B:Particle Size }(\mu) \\
\begin{array}{c}\text { Compressibility } \\
\text { index (\%) }\end{array}\end{array}$ & is in range & 250 & 600 & 1.09648 & 1 & 3 \\
$\begin{array}{c}\text { Disintegration Time } \\
(\text { min) }\end{array}$ & minimize & 1 & 2 & 1 & 0.1 & 3 \\
\begin{tabular}{c} 
Hardness $(\mathrm{kg})$ \\
\hline
\end{tabular} & is in range & 5 & 7 & 1 & 1 & 3 \\
\hline
\end{tabular}

Table 4: Suggested formula based on the set constraints.

\begin{tabular}{|cccccccc|}
\hline Number & $\begin{array}{c}\text { A:Binder } \\
\text { Concentration }(\mathrm{mg})\end{array}$ & $\begin{array}{c}\text { B:Particle } \\
\text { Size }(\mu)\end{array}$ & $\begin{array}{c}\text { Compressibility } \\
\text { Index (\%) }\end{array}$ & $\begin{array}{c}\text { Disintegration } \\
\text { Time }(\mathrm{min})\end{array}$ & $\begin{array}{c}\text { Hardness } \\
(\mathbf{k g})\end{array}$ & Desirability \\
\hline 1 & 2.000 & 385.883 & 19.869 & 1.836 & 7.000 & 0.914 \\
2 & 2.000 & 387.394 & 19.889 & 1.836 & 6.976 & 0.914 \\
3 & 2.000 & 388.642 & 19.905 & 1.837 & 6.955 & 0.913 \\
\hline
\end{tabular}

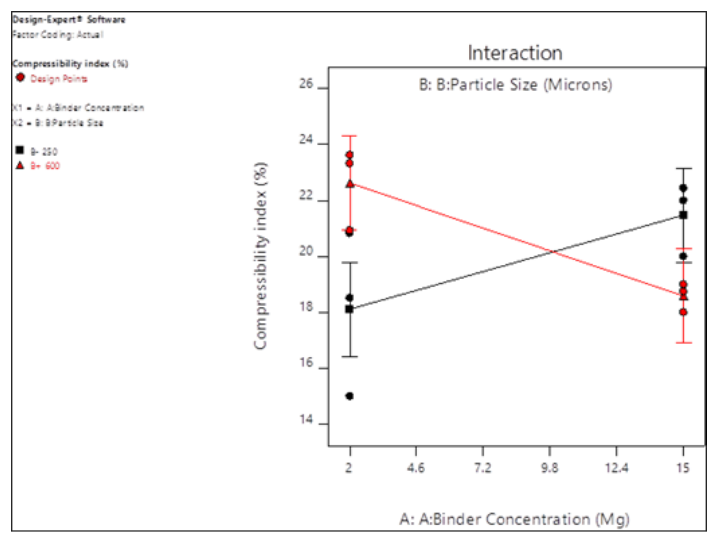

Figure 1: Interaction between $B C$ and particle size on the compressibility index.

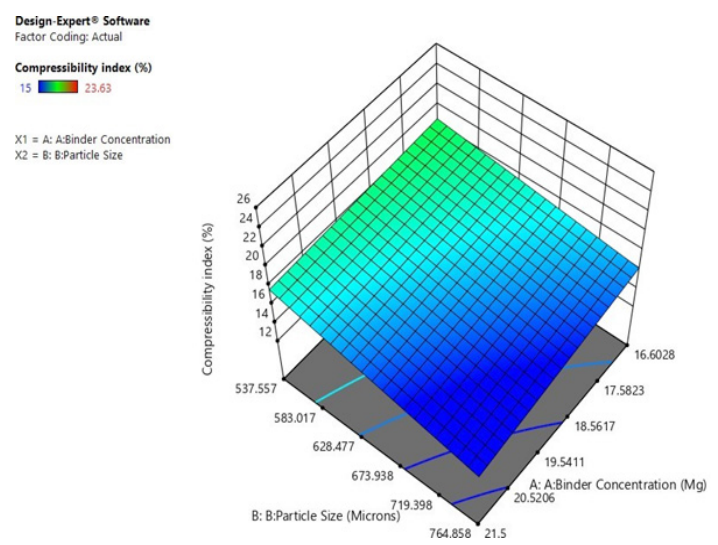

Figure 2: 3D Plot showing the compressibility index.

size must be increased the reason behind this phenomenon might be the granules prepared with the higher concentration of binder might be more rigid and harder than those prepared with lower BC..$^{15}$ The granules with lower $\mathrm{BC}$ is fragile, ${ }^{16}$ also during the studies, it breaks down into fine particles or fine powders. ${ }^{17}$ Whereas at Higher BC as the granules
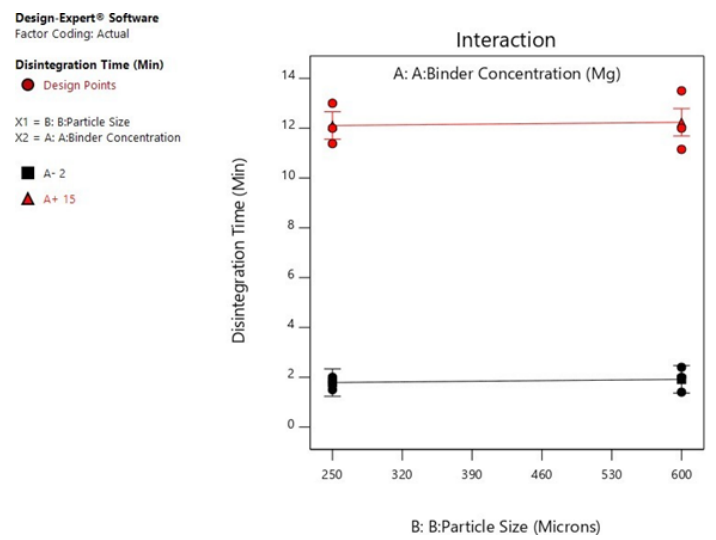

Figure 3: Interaction graph of BC and particle size on DT.
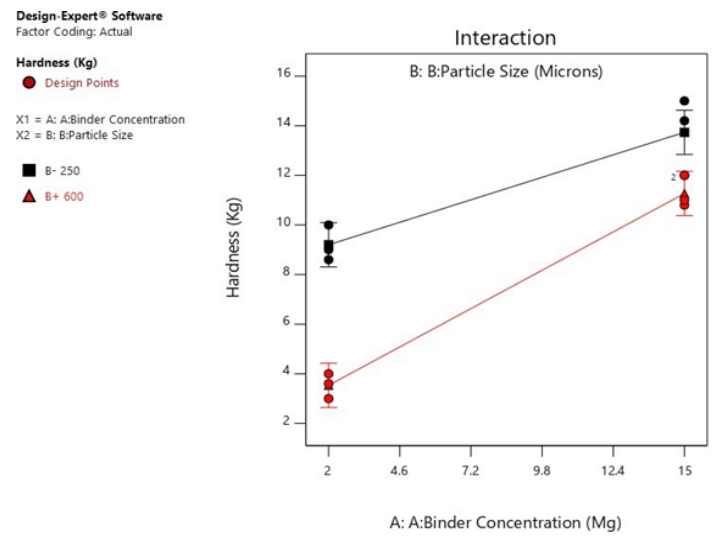

Figure 4: Interaction graph of BC and particle size on Hardness.

are harder thus it maintains rigidity and it is being well packed. ${ }^{18}$ Figure 2 the $3 \mathrm{D}$ plot shows the CI below $16 \%$ can be achieved for the granules prepared with particle size $>670 \mu \mathrm{m}$ and BC $>18.56 \mathrm{mg}$ for PVP K 30 .

Hardness of a tablet is directly proportional to BC. Irrespective of the particle size the hardness increases with increase in $\mathrm{BC} .{ }^{19}$ Comparing 


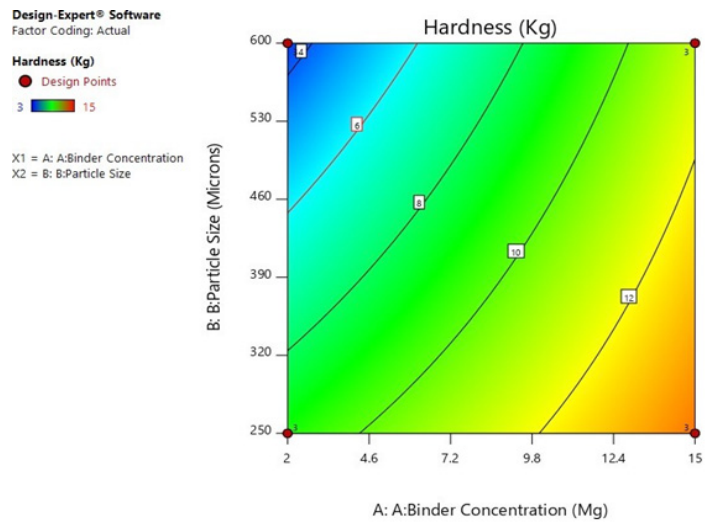

Figure 5: Contour plot -the effect of $B C$ and particle size on Hardness.

the effect of particle size with the binder, lower particle size has higher hardness. Lower the particle size, lesser the void space and more adhesive force whereas higher sized granules have more inter granular space which may reduce the hardness. ${ }^{20}$ Hardness between 4 and $6 \mathrm{~kg}$ can be achieved with minimum BC by setting the particle size of the granules in between $450 \mu$ to $570 \mu$. This concludes the hardness of tablet can be increased by decreasing the particle size. ${ }^{21}$ Based on the experimental results, it is concluded that, the particle size can affect hardness ${ }^{22}$ and $\mathrm{CI},{ }^{23}$ but the $\mathrm{BC}$ has a strong impact on hardness, CI and DT. ${ }^{24}$ Even though particle size does not have a direct impact on DT, it affects the hardness, ${ }^{25}$ which has a greater impact on DT ${ }^{26}$ Combining the factor response relationship, the Design-Expert suggests the following formula under certain constraints for optimization. Table 3 shows the constraints to achieve the low disintegration time, a good hardness and fair flow property. The expected response values include a disintegration time between 1 and 2 min with maximum weightage for lowest time point and an optimum hardness of $5-7 \mathrm{~kg}$ with equal weightage and a fair flow property with CI 10-20\% with equal weightage. The set factor values include a lower BC and particle size range between $250-600 \mu$. Based on the above- prefixed values of factors and responses the suggested formula to get a g good response is given in Table 4, which explains the factor range at which it can produce the optimum results. Three formulas were obtained in the given range with desirability near to 1 . The formula is effective in developing immediate release tablet without a disintegrant or even without any SD only by adjusting the particle size and hardness.

\section{CONCLUSION}

The study was conducted to find an alternative method to reduce the DT of an IR tablet without disintegrants. The study derived a relationship between particle size and BC towards CI, hardness and DT. The study has concluded the following: Compressibility index (CI):- Lower granular size with higher $\mathrm{BC}$ can increase the $\mathrm{CI}$ and higher granular size with higher BC can decrease the CI. Disintegration Time (DT): The granular particle size alone does not affect the DT directly, but a higher granular size decreases the hardness, thus the DT can be reduced. Hardness: The particle size has a direct impact on the hardness of the tablet. At lower particle size the hardness is high and as the size increases the hardness decrease but a proportional increase in hardness with respect to binder concentration. A DT less than $2 \mathrm{~min}$, hardness above $5 \mathrm{~kg}$ and CI around $19 \%$ can easily achieve if the granules are made with 2 mg PVP K30 binder and granular particle of size $380 \mu$. The developed method is more practical to formulate an IR tablet for a highly potent drug without any disintegrant.

\section{ACKNOWLEDGEMENT}

Nil.

\section{CONFLICT OF INTEREST}

The authors declare that there are no conflicts of interest.

\section{ABBREVIATIONS}

API: Active pharmaceutical ingredient; BC: Binder concentration; CI: Compressibility index; DT: Disintegration Time; IR: Immediate release; PVP: Poly vinyl pyrrolidone; SD: Super disintegrants.

\section{REFERENCES}

1. Subrahmanyam CV. Micromeritics. Text book of physical pharmaceutics. Delhi: Vallabh Prakashan. 2014;180-234.

2. Kaur A, Kaur LP. Superdisintegrants: An arising exemplar in orodispersible tablets. Int J Drug Res Tech. 2017;5(1):11.

3. Ghorab MM, Salam HM, El-Sayad MA, Mekhel MM. Tablet formulation containing meloxicam and cyclodextrin: Mechanical characterization and bioavailability evaluation. AAPS Pharm Sci Tech. 2004;5(4):63-71.

4. Wang Z, Sun J, Wang Y, Liu X, Liu Y, Fu Q, et al. Solid self-emulsifying nitrendipine pellets: Preparation and in vitro/in vivo evaluation. Int J Pharm. 2010;383(12):1-6.

5. Bandari S, Mittapalli RK, Gannu R. Orodispersible tablets: An overview. Asian J Pharm. 2014;2(1):1-6.

6. Mohapatra A, Parikh RK, Gohel MC. Formulation, development and evaluation of patient friendly dosage forms of metformin, Part-l: Orally disintegrating tablets. Asian J Pharm. 2014;2(3)

7. Shikata F, Kimura S, Hattori Y, Otsuka M. Real-time monitoring of granule properties during high shear wet granulation by near-infrared spectroscopy with a chemometrics approach. RSC Adv. 2017;7(61):38307-24

8. Sotoyama M, Uchida S, Tanaka S, Hakamata A, Odagiri K, Inui N, et al. Citric Acid Sup- presses the Bitter Taste of Olopatadine Hydrochloride Orally Disintegrating Tablets. Biol Pharm Bull. 2017;40(4):451-8.

9. Patel S, Kaushal AM, Bansal AK. Compression physics in the formulation development of tablets. Crit Rev Ther Drug Carrier Syst. 2006;23(1):1-65.

10. Osorio-Fierros A, Cronin K, Ring D, Mndez-Zavala A, Morales-Oyervides L, Montaez JC. In fluence of granulation process parameters on food tablet properties formulated using natural powders (Opuntia ficus and Chlorella spp). Powder Technol. 2017;317:281-7.

11. Parikh DM. Handbook of pharmaceutical granulation technology. CRC Press. 2016.

12. Gupta A, Mishra AK, Gupta V, Bansal P, Singh R, Singh AK.

13. Recent trends of fast dissolving tablet-an overview of formulation technology. Int J Pharm Biol Arch. 2010;1(1):1-10.

14. Pahwa R, Piplani M, Sharma PC, Kaushik D, Nanda S. Orally disintegrating tablets Friendly to pediatrics and geriatrics. Arch Appl Sci Res. 2010;2(2):35-48.

15. Arafat B, Wojsz M, Isreb A, Forbes RT, Isreb M, Ahmed W, et al. Tablet fragmentation without a disintegrant: A novel design approach for accelerating disintegration and drug release from 3D printed cellulosic tablets. Eur J Pharm Sci. 2018;118:191-200.

16. Rahman Z, Zidan AS, Khan MA. Risperidone solid dispersion for orally disintegrating tablet: Its formulation design and non-destructive methods of evaluation. Int J Pharm. 2010;400(1-2):49-58

17. Parkash V, Maan S, Deepika SK, Hemlata VJ. Fast disintegrating tablets: Opportunity in drug delivery system. J Adv Pharm Technol Res. 2011;2(4):223.

18. Gryczke A, Schminke S, Maniruzzaman M, Beck J, Douroumis D. Development and evaluation of Orally Disintegrating Tablets (ODTs) containing Ibuprofen granules prepared by hot melt extrusion. Colloids Surf B Biointerfaces. 2011;86(2):275-84

19. Jayaramu RA, Boregowda SS, Varma AR, Kalegowda C. Development of fast dispersing tablets of nebivolol: Experimental and computational approaches to study formulation characteristics. Braz J Pharm Sci. 2014;50(4):956-63.

20. Velmurugan S, Vinushitha S. Oral disintegrating tablets: An overview. Int J Chem Phar Sci. 2010;1(2):1-2.

21. Badgujar B, Mundada A. The technologies used for developing orally disintegrat ing tablets: A review. Acta Pharm. 2011;61(2):117-39.

22. Tank D, Karan K, Gajera BY, Dave RH. Investigate the effect of solvents on wet granulation of microcrystalline cellulose using hydroxypropyl methylcellulose as a binder and evaluation of rheological and thermal characteristics of granules. Saudi Pharm J. 2018;26(4):593-602.

23. Kimura SI, Uchida S, Kanada K, Namiki N. Effect of granule properties on rough mouth feel and palatability of orally disintegrating tablets. Int J Pharm. 
2015;484(1- 2):156-62.

24. El-Bagory I, Barakat N, Ibrahim MA, El-Enazi F. Formulation and in vitro evaluation of theophylline matrix tablets prepared by direct compression: Effect of polymer blends. Saudi Pharm J. 2012;20(3):229-67.
25. Jop P. Rheological properties of dense granular flows. CR Phys. 2015;16(1):6272.

26. Sandler N, Wilson D. Prediction of granule packing and flow behavior based on particle size and shape analysis. J Pharm Sci. 2010;99(2):958-68.

Cite this article: Joseph D, Suseem SR. An Investigation through the Pharmacotechnical Factors-To Develop a Method to Replace a Super Disintegrant in an Immediate Release Tablet. Int. J. Pharm. Investigation. 2020;9(4):164-8. 